\title{
Determination of optimal geometrical parameters of peripheral mills to achieve good process stability
}

\author{
Min Wan ${ }^{1,2} \cdot$ Heng Yuan ${ }^{1,2} \cdot$ Ying-Chao Ma ${ }^{1,2} \cdot$ Wei-Hong Zhang ${ }^{1,2}$
}

Received: 4 September 2017 / Accepted: 26 April 2018/Published online: 18 May 2018

(C) The Author(s) 2018

\begin{abstract}
This paper focuses on optimization of the geometrical parameters of peripheral milling tools by taking into account the dynamic effect. A substructure synthesis technique is used to calculate the frequency response function of the tool point, which is adopted to determine the stability lobe diagram. Based on the Taguchi design method, simulations are first conducted for varying combinations of tool overhang length, helix angle, and teeth number. The optimal geometrical parameters of the tool are determined through an orthogonal analysis of the maximum axial depth of cut, which is obtained from the predicted stability lobe diagram. It was found that the sequence of every factor used to determine the optimal tool geometrical parameters is the tool overhang length, teeth number, and helix angle. Finally, a series of experiments were carried out as a parameter study to determine the influence of the tool overhang length, helix angle, and teeth number on the cutting stability of a mill. The same conclusion as that obtained through the simulation was observed.
\end{abstract}

Min Wan

m.wan@nwpu.edu.cn

Wei-Hong Zhang

zhangwh@nwpu.edu.cn

1 School of Mechanical Engineering, Northwestern Polytechnical University, Xi' an 710072, Shaanxi, People's Republic of China

2 State IJR Center of Aerospace Design and Additive Manufacturing, Northwestern Polytechnical University, Xi' an 710072, Shaanxi, People's Republic of China
Keywords Substructure synthesis technique - Frequency response function - Tool geometrical parameter - Taguchi design method

\section{Introduction}

Milling, which has the advantage of a large material removal rate, high efficiency, and high accuracy, is an advanced material processing technology that is widely used in the aerospace and automotive industries, among others. Chatter vibration is a type of self-excited vibration, which consistently destroys the stability of the cutting, aggravates the tool wear, and reduces the efficiency and accuracy [1]. The occurrence of regenerative chatter is common in industry, and its avoidance has been greatly investigated [2-4]. A stability lobe diagram (SLD) is often used to select the proper cutting parameters and ensure the stability and high efficiency during the cutting process. Along with an SLD, the geometrical tool parameters have an important effect on the stability of the cutting. Thus, it is of significant importance to study such parameters in terms of stability.

Erturk et al. [5] adopted Timoshenko's beam theory to calculate the tool's dynamic characteristics, whereas Zhou et al. [6] used the finite element method to study the dynamic characteristics of a cutting tool for use in highspeed milling. Both studies also investigated the effects of tool dynamics on the chatter stability. Engin and Altintas [7] proposed a generalized mathematical model by considering the dynamic characteristics of general milling cutters. In addition, Altintas et al. [8], Budak [9], Sellmeier and Denkena [10] investigated the tool stability under variable pitches and obtained good results. Shirase and Altintas [11] obtained the optimal pitch for efficiently reducing vibration and surface errors by studying the 
milling process of a non-pitched cutter. Dombovari and Stepan [12] explored the behavior of non-uniform and harmonically varied helix cutters in applications with a high or low cutting speed. Subramanian et al. [13] optimized the end mill geometrical tool parameters based on the vibration amplitude, and obtained optimal values. $\mathrm{Li}$ and Liu [14] studied the influences of some uncertain factors in a machine tool system on an SLD through an experimental modal analysis and simulations, and concluded that the flute length, cutter overhang, and cutter teeth number are the main geometrical cutter factors affecting the chatter stability. Wei et al. [15] pointed out that the geometrical tool parameters have an influence on the vibration, and concluded that the sampling frequency of the dynamic cutting force spectrum reduced with a decrease in the teeth number and an increase in the tooth unevenness. As a result, the energy generated by vibrations while cutting was dispersed and the stability of cutting process was therefore enhanced. Neseli et al. [16] used a response surface methodology to optimize geometrical tool parameters. Alauddin and Baradie [17] indicated that the helix angle, rake angle, clearance angle, nose radius, and number of teeth are the main factors most significantly influencing the tool life during certain machine processes. Zeng et al. [18] researched the influence of the geometrical parameters of a carbide end mill on the cutting force in the milling of titanium alloy TC18, and provided the basis for further optimization. In summary, the above works prove that the geometrical tool parameters are important parameters that influence the performance of the cutting process.

The main aim of this work is to study the influence of the sequence of geometrical tool parameters applied, i.e., the tool overhang, helix angle, and teeth number, on the process stability, and to then determine the optimal combination of such parameters, thereby ensuring a good dynamic performance of the helical milling processes. The remainder of this paper is organized as follows. Theoretical formulae for calculating the frequency response function (FRF) and an SLD are described in Sect. 2. In Sect. 3, the optimal geometrical tool parameters are investigated based on the Taguchi design method. A series of verification experiments carried out are described in Sect. 4. Finally, some concluding remarks are provided in Sect. 5.

\section{Dynamic model of milling process}

\subsection{Calculation of frequency response function of tool-holder-spindle}

Figure 1 shows a typical illustration of a machine tool system containing four components, i.e., a spindle-holder $(\mathrm{P})$, joint interface $(\mathrm{J})$, tool shank $(\mathrm{S})$, and tool edge $(\mathrm{E})$.

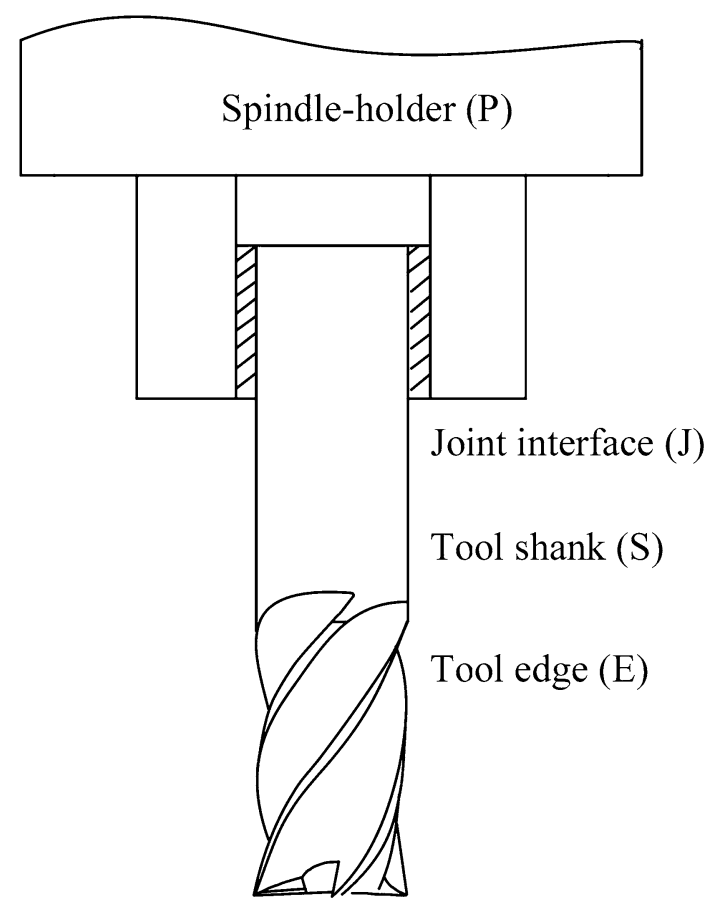

Fig. 1 Typical illustration of a tool-holder-spindle system in milling

These components are separated into sets of nodes for the convenience of applying a finite analysis method. The joint interface is modeled as a distributed layer with zero thickness, which is the connecting medium between the tool and holder. A substructure synthesis technique is applied to predict the FRF of the tool point.

The dynamics of these four components can be expressed as follows

$\boldsymbol{X}_{\mathrm{P}}(\omega)=\boldsymbol{G}_{\mathrm{P}}(\omega) \boldsymbol{F}_{\mathrm{P}}(\omega)$,

$\boldsymbol{M}_{\mathrm{B}} \ddot{\boldsymbol{X}}_{\mathrm{B}}(t)+\boldsymbol{C}_{\mathrm{B}} \dot{\boldsymbol{X}}_{\mathrm{B}}(t)+\boldsymbol{K}_{\mathrm{B}} \boldsymbol{X}_{\mathrm{B}}(t)=\boldsymbol{F}_{\mathrm{B}}(t)$.

Equation (1) denotes the dynamics of the spindle-holder, whereas Eq. (2) denotes the dynamics of the joint interface, the tool shank, and the tool edge. In addition, $\boldsymbol{G}_{\mathrm{P}}(\omega)$ is the FRF matrix of the spindle-holder, which can be obtained using the method reported in Ref. [19], $\boldsymbol{X}_{\mathrm{P}}(\omega)$ is the deflection vector of the spindle-holder, $\boldsymbol{F}_{\mathrm{P}}(\omega)$ is the force vector of the spindle-holder applied by the joint interface. $\boldsymbol{M}_{\mathrm{B}}, \boldsymbol{C}_{\mathrm{B}}, \boldsymbol{K}_{\mathrm{B}}, \boldsymbol{X}_{\mathrm{B}}$, and $\boldsymbol{F}_{\mathrm{B}}(\mathrm{B}=\mathrm{J}, \mathrm{S}$, or E) are the mass matrix, damping matrix, stiffness matrix, deflection vector, and force vector of the joint interface, tool shank, or tool edge, respectively. Finally, $\boldsymbol{M}_{\mathrm{J}}$ equals zero because the joint interface has zero thickness.

Equation (1) can be rewritten as

$\boldsymbol{L}_{\mathrm{P}}(\omega) \boldsymbol{X}_{\mathrm{P}}(\omega)=\boldsymbol{F}_{\mathrm{P}}(\omega)$,

where $\boldsymbol{L}_{\mathrm{P}}(\omega)=G_{\mathrm{P}}^{-1}(\omega)$.

Equation (2) can be rearranged in the frequency domain as 
$\left(-\omega^{2} \boldsymbol{M}_{\mathrm{A}}+\omega \mathrm{j} \boldsymbol{C}_{\mathrm{A}}+\boldsymbol{K}_{\mathrm{A}}\right) \boldsymbol{X}_{\mathrm{A}}(\omega)=\boldsymbol{F}_{\mathrm{A}}(\omega)$,

where $\boldsymbol{M}_{\mathrm{A}}=\left[\begin{array}{ccc}0 & 0 & 0 \\ 0 & \boldsymbol{M}_{\mathrm{S}} & 0 \\ 0 & 0 & \boldsymbol{M}_{\mathrm{E}}\end{array}\right], \quad \boldsymbol{C}_{\mathrm{A}}=\left[\begin{array}{ccc}\boldsymbol{C}_{\mathrm{J}} & 0 & 0 \\ 0 & \boldsymbol{C}_{\mathrm{S}} & 0 \\ 0 & 0 & \boldsymbol{C}_{\mathrm{E}}\end{array}\right]$,

$\boldsymbol{K}_{\mathrm{A}}=\left[\begin{array}{ccc}\boldsymbol{K}_{\mathrm{J}} & 0 & 0 \\ 0 & \boldsymbol{K}_{\mathrm{S}} & 0 \\ 0 & 0 & \boldsymbol{K}_{\mathrm{E}}\end{array}\right], \quad \boldsymbol{X}_{\mathrm{A}}=\left[\begin{array}{c}\boldsymbol{X}_{\mathrm{J}} \\ \boldsymbol{X}_{\mathrm{S}} \\ \boldsymbol{X}_{\mathrm{E}}\end{array}\right], \quad \boldsymbol{F}_{\mathrm{A}}=\left[\begin{array}{c}\boldsymbol{F}_{\mathrm{J}} \\ \boldsymbol{F}_{\mathrm{S}} \\ \boldsymbol{F}_{\mathrm{E}}\end{array}\right]$

Combining Eqs. (3) and (4) leads to the following dynamics of the machine tool system.

$\boldsymbol{R}(\omega) \boldsymbol{X}(\omega)=\boldsymbol{F}(\omega)$

where $\quad \boldsymbol{R}(\omega)=-\omega^{2}\left[\begin{array}{cc}0 & 0 \\ 0 & \boldsymbol{M}_{\mathrm{A}}\end{array}\right]+\omega \mathrm{j}\left[\begin{array}{cc}0 & 0 \\ 0 & \boldsymbol{C}_{\mathrm{A}}\end{array}\right]+\left[\begin{array}{cc}\boldsymbol{L}_{\mathrm{P}} & 0 \\ 0 & \boldsymbol{K}_{\mathrm{A}}\end{array}\right]$,

$\boldsymbol{X}(\omega)=\left[\begin{array}{l}\boldsymbol{X}_{\mathrm{P}}(\omega) \\ \boldsymbol{X}_{\mathrm{A}}(\omega)\end{array}\right], \boldsymbol{F}(\omega)=\left[\begin{array}{l}\boldsymbol{F}_{\mathrm{P}}(\omega) \\ \boldsymbol{F}_{\mathrm{A}}(\omega)\end{array}\right]$.

Equation (5) can be rearranged as

$\boldsymbol{T}^{\mathrm{T}} \boldsymbol{R}(\omega) \boldsymbol{T} \boldsymbol{X}^{\prime}(\omega)=\boldsymbol{T}^{\mathrm{T}} \boldsymbol{F}(\omega)$

where $\boldsymbol{T}$ is a transformation matrix that makes the dependent coordinates independent, and $\boldsymbol{X}(\omega)=\boldsymbol{T} \boldsymbol{X}^{\prime}(\omega)$.

Finally, the FRF matrix $\boldsymbol{N}(\omega)$ can be obtained as

$\boldsymbol{N}(\omega)=\left(\boldsymbol{T}^{\mathrm{T}} \boldsymbol{R}(\omega) \boldsymbol{T}\right)^{-1}$.

\subsection{Prediction of SLDs}

In this section, SLDs are drawn using an updated zeroorder semi-discretization method [20, 21], which is briefly described as follows.

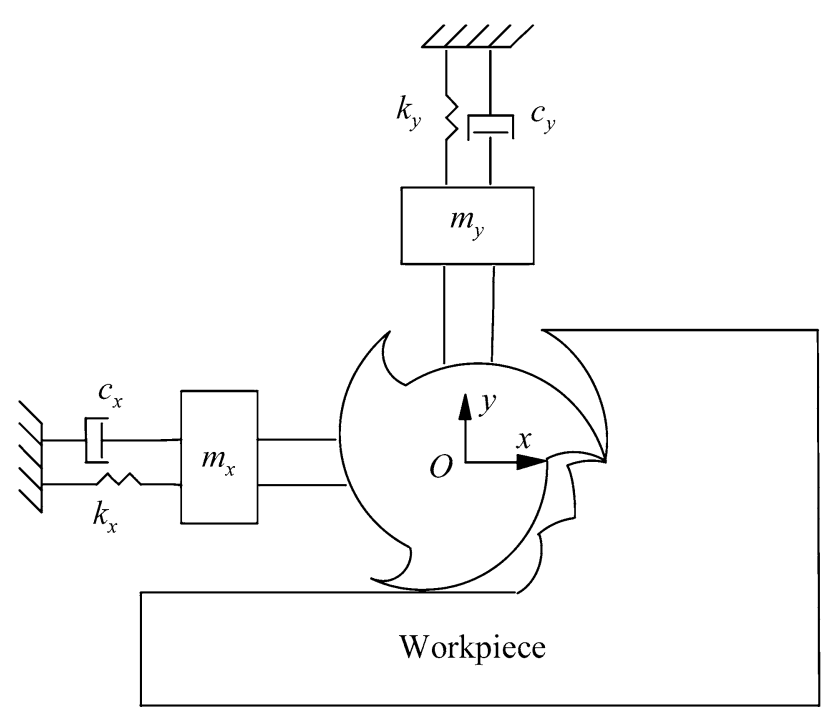

Fig. 2 Typical dynamic milling system with two degrees of freedom
The governing equation of a two-degree milling process, which is schematically shown in Fig. 2, is written as

$\boldsymbol{M} \ddot{\boldsymbol{Q}}(t)+\boldsymbol{C} \dot{\boldsymbol{Q}}(t)+\boldsymbol{K} \boldsymbol{Q}(t)=\boldsymbol{G}(t) \boldsymbol{Q}(t)-\boldsymbol{G}(t) \boldsymbol{Q}(t-\tau)$,

where $\boldsymbol{M}=\operatorname{diag}\left(m_{x}, m_{y}\right), \quad \boldsymbol{C}=\operatorname{diag}\left(c_{x}, c_{y}\right), \quad \boldsymbol{K}=\operatorname{diag}$ $\left(k_{x}, k_{y}\right)$, and $\boldsymbol{Q}(t)=[x(t), y(t)]^{\mathrm{T}}$. In addition, $\boldsymbol{G}(t)$ is a coefficient matrix obtained in Ref. [20].

The first-order representation of the system can be expressed as

$\dot{\boldsymbol{U}}(t)=\boldsymbol{A}(t) \boldsymbol{U}(t)+\boldsymbol{B}(t) \boldsymbol{U}(t-\tau)$,

where $\quad \boldsymbol{A}(t)=\left[\begin{array}{cc}\boldsymbol{O}_{2 \times 2} & \mathbf{I}_{2 \times 2} \\ \boldsymbol{M}^{-1}[\boldsymbol{G}(t)-\boldsymbol{K}] & -\boldsymbol{M}^{-1} \boldsymbol{C}\end{array}\right], \boldsymbol{B}(t)=$ $\left[\begin{array}{cc}\boldsymbol{O}_{2 \times 2} & \boldsymbol{O}_{2 \times 2} \\ -\boldsymbol{M}^{-1} \boldsymbol{G}(t) & \boldsymbol{O}_{2 \times 2}\end{array}\right], \boldsymbol{U}(t)=\left[\begin{array}{c}\boldsymbol{Q}(t)^{\mathrm{T}} \\ \dot{\boldsymbol{Q}}(t)^{\mathrm{T}}\end{array}\right], \quad$ and $\quad \boldsymbol{O}_{2 \times 2} \quad$ and

$\boldsymbol{I}_{2 \times 2}$ are zero and identity matrices, respectively.

Dividing the cutting period $T$ into $w$ uniform discrete time intervals leads to $\Delta t=T / w$. The solution to Eq. (9) over one discrete step can be approximated as follows.

$\boldsymbol{U}_{n+1}=\boldsymbol{P}_{n} \boldsymbol{U}_{n}+\frac{1}{2} \boldsymbol{R}_{n} \boldsymbol{U}_{n-m+1}+\frac{1}{2} \boldsymbol{R}_{n} \boldsymbol{U}_{n-m}$,

where $\quad \boldsymbol{U}_{n}=\boldsymbol{U}(n \Delta t), \boldsymbol{P}_{n}=\mathrm{e}^{\boldsymbol{A}\left(t_{n}\right) \Delta t}, \boldsymbol{R}_{n}=\left(\boldsymbol{P}_{n}-\boldsymbol{I}\right)\left(\boldsymbol{A}\left(t_{n}\right)\right)^{-1}$ $\boldsymbol{B}\left(t_{n}\right)$, and $m$ is the number of intervals related to the delay item $\tau$.

The results of coupling solutions of $w$ successive time intervals over one period $T$ can be expressed as follows

$\left\{\begin{array}{l}\boldsymbol{V}_{w}=\boldsymbol{\Phi} \boldsymbol{V}_{0}, \\ \boldsymbol{V}_{n}=\left[\boldsymbol{U}_{n}^{\mathrm{T}}, \boldsymbol{U}_{n-1}^{\mathrm{T}}, \cdots, \boldsymbol{U}_{n-m}^{\mathrm{T}}\right]^{\mathrm{T}} \\ \boldsymbol{\Phi}=\left[\boldsymbol{D}_{w-1} \boldsymbol{D}_{w-2}, \boldsymbol{D}_{w-3} \boldsymbol{D}_{w-4}, \cdots, \boldsymbol{D}_{1} \boldsymbol{D}_{0}\right]\end{array}\right.$

where $\boldsymbol{D}_{n}$ is the coefficient matrix and can be expressed as follows

$$
\boldsymbol{D}_{n}=\left[\begin{array}{ccccccc}
\boldsymbol{P}_{n} & 0 & 0 & \cdots & 0 & \frac{1}{2} \boldsymbol{R}_{n} & \frac{1}{2} \boldsymbol{R}_{n} \\
\boldsymbol{I} & 0 & 0 & \cdots & 0 & 0 & 0 \\
0 & \boldsymbol{I} & 0 & \cdots & 0 & 0 & 0 \\
\vdots & \vdots & \vdots & \ddots & \vdots & \vdots & \vdots \\
0 & 0 & 0 & \cdots & 0 & 0 & 0 \\
0 & 0 & 0 & \cdots & \boldsymbol{I} & 0 & 0 \\
0 & 0 & 0 & \cdots & 0 & \boldsymbol{I} & 0
\end{array}\right] .
$$

If all eigenvalues of $\boldsymbol{\Phi}$ are less than 1 in the modulus, then the system is stable. It should be noted that, because interrupted machining, i.e., milling, is considered in the following study, the prediction accuracy of the semi-discretization method described above can be ensured using an interval number with a relatively large value, as observed from the results reported in Ref. [22]. 


\section{Tool parameter optimization based on Taguchi design method}

The Taguchi design method is a multi-factor and multilevel design method, which selects representative points from full fractional tests based on the orthogonality. This method is much more efficient and effective than a fractional factorial design [23]. The parameter design of the Taguchi method mainly includes the following steps [24]: (i) selection of the design parameters to be evaluated, and determination of the number of levels for the design parameters; (ii) assignment of the design parameters to an orthogonal array, and experiments conducted based on the arrangement of the orthogonal array; and (iii) analysis of the experimental results. As Selvaraj and Chandramohan [25] noted, the Taguchi method has been used to study the performance of various machining operations, e.g., turning and end milling, in various alloys using various cutting tools. In the following study, the Taguchi method is also used to study the influence of the cutting parameters on the cutting stability.

Orthogonal tests to be conducted with different combinations of parameters are usually set into a table, i.e., an orthogonal array, which is used to analyze and select the optimal values of the factors. In an orthogonal array, the numbers of any levels on any columns are equal, as are the numbers of all possible combinations of the various levels on any two columns. As a result, when the effect of each level in each column is regarded, the interference of other factors can be excluded. One can then comprehensively compare the effects produced by different levels in each column.

\subsection{Experimental factors and orthogonal array}

In the cutting process, the geometrical parameters of the tool, i.e., the tool overhang, helix angle, and teeth number, have an important effect on the dynamics of the machine tool system. Thus, they are selected to study the influence of geometrical tool parameters on the cutting stability and choose the optimal tool geometrical parameters during cutting. With respect to the overhang of the tool, three typical design parameters, namely, $50 \mathrm{~mm}, 70 \mathrm{~mm}$, and $100 \mathrm{~mm}$ overhangs, are used, whereas tools with two, three, and four teeth are selected. In addition, angles of $30^{\circ}$, $40^{\circ}$, and $50^{\circ}$, which are commonly used in the industry, are applied as the helix angles. By doing so, the control factors are chosen, and each control factor has three variables, which are called the "three factors-three levels" as shown in Table 1. It should be noted that the tool diameter has an important influence on the machining stability. For a certain machining process, the tool diameter is usually
Table 1 Control factors and level values used for orthogonal array

\begin{tabular}{lcll}
\hline Control factors & Overhang/mm & Helix angle $/\left(^{\circ}\right)$ & Teeth number \\
\hline Level 1 & 100 & 50 & 2 \\
Level 2 & 70 & 40 & 3 \\
Level 3 & 50 & 30 & 4 \\
\hline
\end{tabular}

determined before the actual cutting. Based on this fact, this study did not investigate the influence of the tool diameter, and only included the other geometrical parameters. The tool diameter used is $12 \mathrm{~mm}$.

According to the control factors and level values listed in Table 1 , a standardized $L_{9}\left(3^{3}\right)$ orthogonal array is designed, as listed in Table 2. In the nine sets of parameters, the three levels of helix angle and teeth number are included in the level of tool overhang factor. Although the combinations are different, the two factors of helix angle and teeth number are at the same position. When the tool overhang factor is used, the effects of different levels of helix angle are offset by each other, as is the effect of the different teeth numbers. Thus, the three levels of tool overhang factor have a comprehensive comparability, as do the three levels of helix angle and teeth number, similarly.

\subsection{FRF and SLD simulations}

In this Section, the FRFs of the different combinations listed in Table 2 are first calculated. By executing the simulations described in Sect. 2, the FRFs in the $x$ and $y$ directions for each combination in Table 2 are simulated, and the results are shown in Figs. 3-5. From Figs. 3-5, it can be seen that there exist clear differences among the dynamic characteristics of the tools with the same overhang but different numbers of teeth and helix angles. Modal parameters in $x$ and $y$ directions are extracted using CutPro ${ }^{\mathrm{TM}}$. Note here that $\mathrm{CutPro}^{\mathrm{TM}}$ is

Table 2 Experimental design using $L_{9}\left(3^{3}\right)$ orthogonal array

\begin{tabular}{llll}
\hline $\begin{array}{l}\text { Test } \\
\text { No. }\end{array}$ & Overhang/mm & Helix angle $/\left(^{\circ}\right)$ & Teeth number \\
\hline 1 & 100 & 50 & 2 \\
2 & 100 & 40 & 3 \\
3 & 100 & 30 & 4 \\
4 & 70 & 50 & 3 \\
5 & 70 & 40 & 4 \\
6 & 70 & 30 & 2 \\
7 & 50 & 50 & 4 \\
8 & 50 & 40 & 2 \\
9 & 50 & 30 & 3
\end{tabular}




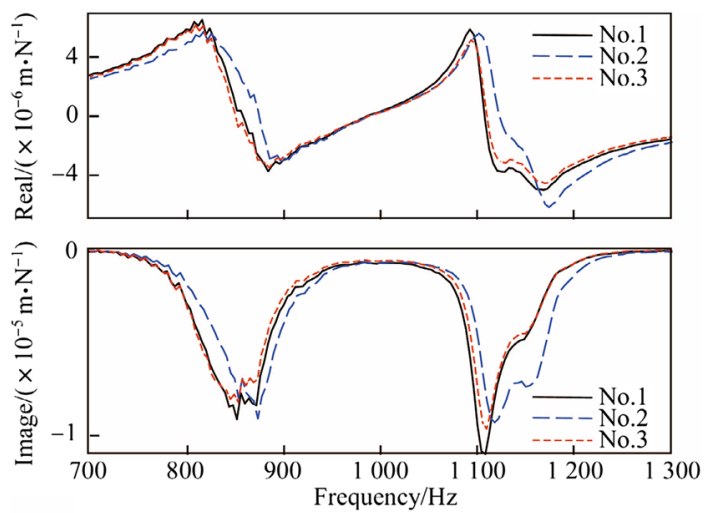

(a) $x$ direction

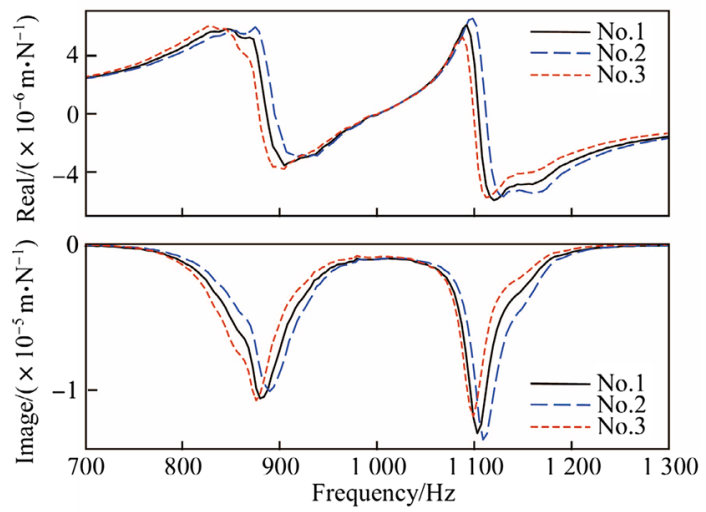

(b) $y$ direction

Fig. 3 FRFs of test Nos. 1-3 with tool overhang of $100 \mathrm{~mm}$

used for obtaining the modal mass, damping ration, and stiffness, and in the experiments conducted in Sect. 4, is used to measure and analyze the sound signals of the cutting processes. Finally, SLDs are drawn by means of the basic semi-discretization method described in Sect. 2.2, as shown in Figs. 6-8.

From the SLD results, it can be observed that some SLDs for a tool with a $50 \mathrm{~mm}$ overhang have a smaller critical depth of cut than a tool with a $70 \mathrm{~mm}$ overhang, the reason for which is as follows. An SLD is related not only to the system's FRF but also to other parameters such as the number of teeth. This means that, under the combined effect of the FRF and teeth number, the final SLD is generated. That is, although the influence of the teeth number is implicitly included in the FRF, it also contributes to the construction of an SLD. It should be mentioned that the number of teeth for a tool with an overhang of $50 \mathrm{~mm}$ differs from a tool with a $70 \mathrm{~mm}$ overhang. As a result, the SLD for a tool with a $50 \mathrm{~mm}$ overhang has a smaller critical depth of cut than a tool with a $70 \mathrm{~mm}$ overhang.

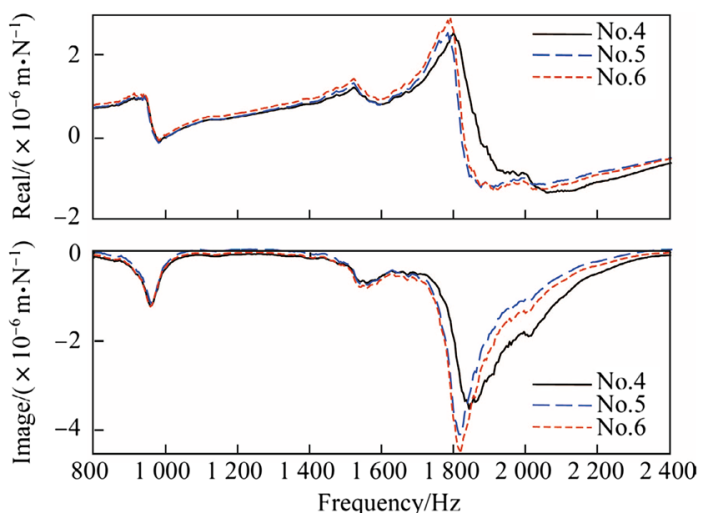

(a) $x$ direction

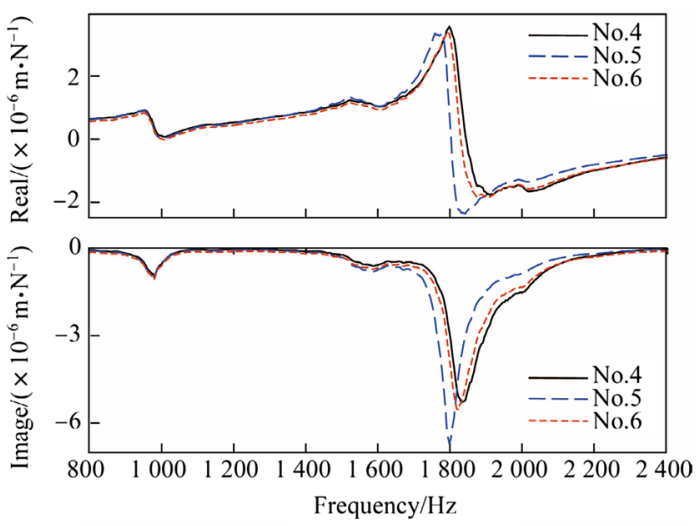

(b) $y$ direction

Fig. 4 FRFs of test Nos. 4-6 with tool overhang of $70 \mathrm{~mm}$

\subsection{Results and discussions}

It is known that the relationship between the axial depth of a cut and the spindle speed can be found from an SLD. A larger axial depth of a cut indicates higher efficiency as long as the spindle speed lies within the permitted range of the machine tool. Thus, the maximum axial depth of a cut is selected as an index to evaluate whether the optimal geometrical tool parameters are applicable. Without a loss of generality, two groups of spindle speeds are selected for analysis, i.e., $3000 \mathrm{r} / \mathrm{min}$ and $8000 \mathrm{r} / \mathrm{min}$, and $3000 \mathrm{r} / \mathrm{min}$ and $12000 \mathrm{r} / \mathrm{min}$. For each combination in an orthogonal array, the maximum axial depth of a cut is determined from the SLDs for each group of spindle speeds, and the results of which are shown in Table 3 . In Table $3, a_{1}$ and $a_{2}$ denote the maximum axial depth of a cut corresponding to a group of $3000 \mathrm{r} / \mathrm{min}$ and $8000 \mathrm{r} / \mathrm{min}$, and $3000 \mathrm{r} / \mathrm{min}$ and $12000 \mathrm{r} / \mathrm{min}$, spindle speeds, respectively. Based on the values of $a_{1}$ and $a_{2}$ in Table 3 , an orthogonal analysis is conducted, the results of which are listed in Tables 4 and 5, respectively.

In Tables 4 and $5, K$ denotes the sum of the three level results for the nine tests, where $k=K / 3$, which is the average of these results, and $R=k_{\max }-k_{\min }$, which 


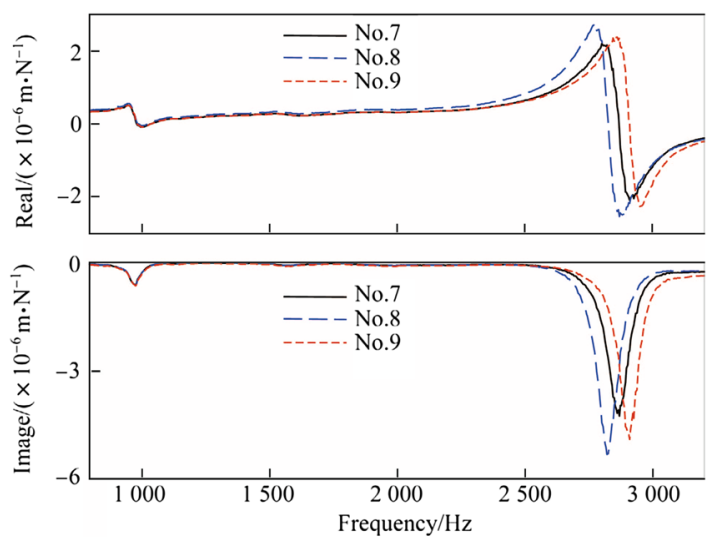

(a) $x$ direction
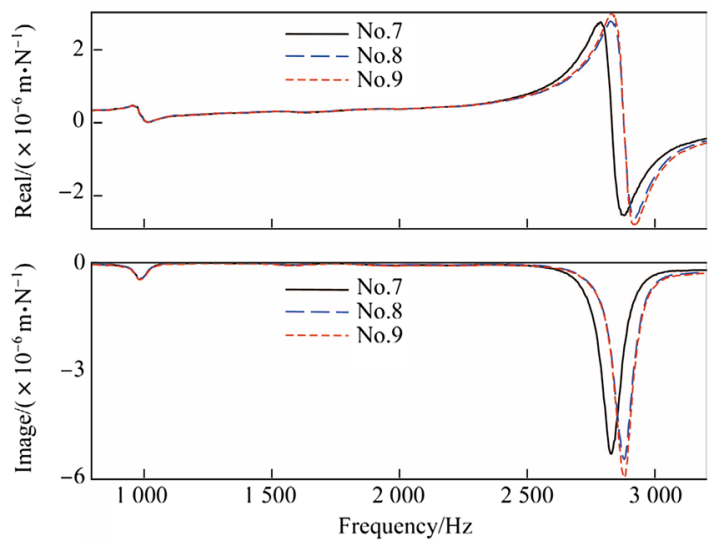

(b) $y$ direction

Fig. 5 FRFs of test Nos. 7-9 with tool overhang of $50 \mathrm{~mm}$

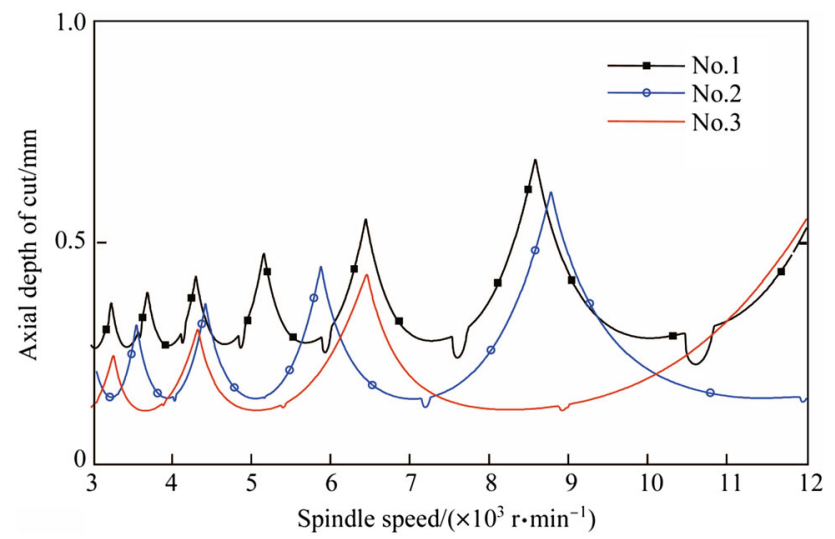

Fig. 6 SLDs of test Nos. 1-3 with tool overhang of $100 \mathrm{~mm}$

represents the range between the three levels for any factor and the importance of the three control factors. The percentage of $R$ under each control factor is calculated to directly show which factor is the dominant one. Based on the value of $k$ in Tables 4 and 5, the selection of a $50 \mathrm{~mm}$ tool overhang is better than a $70 \mathrm{~mm}$ or $100 \mathrm{~mm}$ overhang. In addition, a helix angle of $30^{\circ}$ is better than $40^{\circ}$ or $50^{\circ}$.

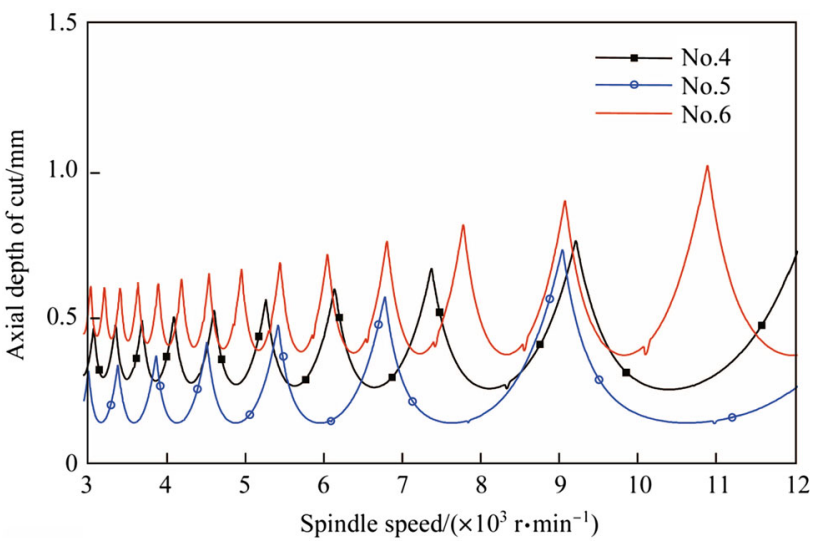

Fig. 7 SLDs of test Nos. 4-6 with tool overhang of $70 \mathrm{~mm}$

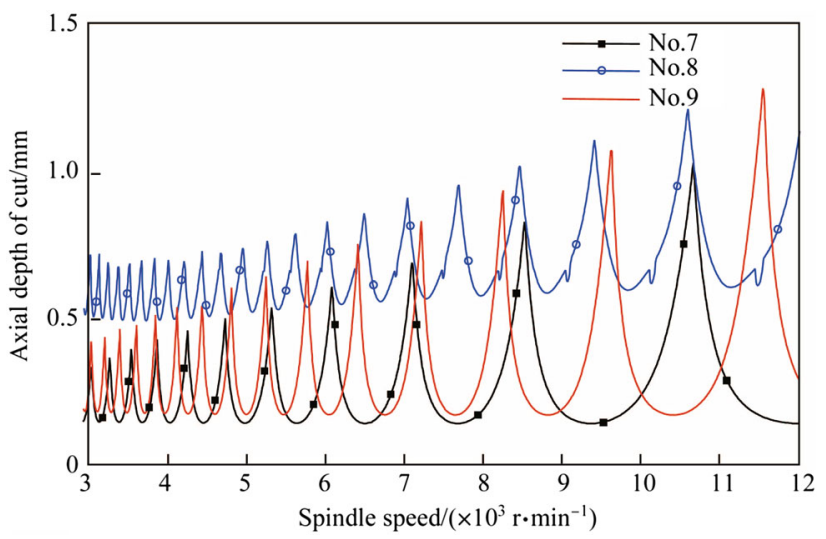

Fig. 8 SLDs of test Nos. 7-9 with tool overhang of $50 \mathrm{~mm}$

For the teeth number, the selection of two teeth is better than three or four. That is, the optimal tool geometrical parameters are a tool overhang of $50 \mathrm{~mm}$, helix angle of $30^{\circ}$, and two teeth. In addition, the sequence of the three control factors is determined by analyzing the percentage of $R$ under each control factor. It was found that the tool overhang is the most significant factor among the three, with the number of teeth being second. The helix angle has the smallest effect on the cutting stability.

\section{Experiment validation}

To verify the conclusions obtained above, a series of milling tests were conducted in a three-axis $\mathrm{CNC}$ machining center with different combinations of geometrical tool parameters. The geometrical parameters of the tools used in the tests are listed in Table 6. The experiments, which were used to research the effects of the tool overhang, helix angle, and teeth number, were carried out separately. The 
Table 3 Results of the $L_{9}\left(3^{3}\right)$ simulations

\begin{tabular}{|c|c|c|c|c|c|}
\hline $\begin{array}{l}\text { Test } \\
\text { No. }\end{array}$ & Overhang/mm & Helix angle $/\left(^{\circ}\right)$ & Teeth number & $a_{1} / \mathrm{mm}$ & $a_{2} / \mathrm{mm}$ \\
\hline 1 & 100 & 50 & 2 & 0.55 & 0.69 \\
\hline 2 & 100 & 40 & 3 & 0.45 & 0.62 \\
\hline 3 & 100 & 30 & 4 & 0.43 & 0.50 \\
\hline 4 & 70 & 50 & 3 & 0.65 & 0.75 \\
\hline 5 & 70 & 40 & 4 & 0.57 & 0.72 \\
\hline 6 & 70 & 30 & 2 & 0.80 & 1.02 \\
\hline 7 & 50 & 50 & 4 & 0.69 & 1.03 \\
\hline 8 & 50 & 40 & 2 & 0.95 & 1.21 \\
\hline 9 & 50 & 30 & 3 & 0.83 & 1.28 \\
\hline
\end{tabular}

Table 4 Orthogonal analysis corresponding to spindle speed from $3000 \mathrm{r} / \mathrm{min}$ to $8000 \mathrm{r} / \mathrm{min}$

\begin{tabular}{lccc}
\hline Control factors & Overhang/mm & Helix angle/ $\left(^{\circ}\right)$ & Teeth number \\
\hline$K$ & $100: 1.43$ & $50: 1.89$ & 2 teeth:2.30 \\
$K$ & $70: 2.02$ & $40: 1.97$ & 3 teeth:1.93 \\
$K$ & $50: 2.47$ & $30: 2.06$ & 4 teeth:1.69 \\
$k$ & $100: 0.48$ & $50: 0.63$ & 3 teeth:0.77 \\
$k$ & $70: 0.67$ & $40: 0.66$ & 3 teeth:0.64 \\
$k$ & $50: 0.82$ & $30: 0.69$ & 0.21 \\
$R$ & 0.34 & 0.06 & 34 \\
Percentage & 56 & 10 & 2 \\
Sequence of control factor & Overhang $>$ Teeth number $>$ Helix angle & 30 \\
Optimal level & 50 & & \\
Optimal combination & 50 mm overhang, $30^{\circ}$ and 2 teeth & \\
\hline
\end{tabular}

Table 5 Orthogonal analysis corresponding to spindle speed from $3000 \mathrm{r} / \mathrm{min}$ to $12000 \mathrm{r} / \mathrm{min}$

\begin{tabular}{llcc}
\hline Control factors & Overhang/mm & Helix angle/ $\left({ }^{\circ}\right)$ & Teeth number \\
\hline$K$ & $100: 1.81$ & $50: 2.47$ & 2 teeth:2.92 \\
$K$ & $70: 2.49$ & $40: 2.55$ & 3 teeth:2.65 \\
$K$ & $50: 3.52$ & $30: 2.80$ & 4 teeth:2.25 \\
$k$ & $100: 0.60$ & $50: 0.82$ & 2 teeth:0.97 \\
$k$ & $70: 0.83$ & $40: 0.85$ & 3 teeth:0.88 \\
$k$ & $50: 1.17$ & $30: 0.93$ & 4 teeth:0.75 \\
$R$ & 0.57 & 0.11 & 0.22 \\
Percentage & 63 & 12 & 25 \\
Sequence of control factor & Overhang $>$ Teeth number $>$ Helix angle & 2 \\
Optimal level & 50 & 30 & \\
Optimal combination & 50 mm overhang, $30^{\circ}$ and 2 teeth & \\
\hline
\end{tabular}

sounds were measured using a microphone. If the dominant frequency of the spectra is an integer multiple of the spindle or tooth passing frequency, the cutting process can be determined as stable [26]. Otherwise, the cutting process is deemed unstable. Figure 9 shows the setup used during the experiments, in which a spindle speed of $4000 \mathrm{r} / \mathrm{min}$, feed per tooth of $0.05 \mathrm{~mm} /$ tooth, and radial depth of cut of $6 \mathrm{~mm}$ were used as the initial cutting parameters.

To study the influence of the tool overhang, tool Nos. 1, 2 , and 7, listed in Table 6, were used. Tool Nos. 2-4 were 
Table 6 Geometrical parameters of tools used in the tests

\begin{tabular}{llll}
\hline $\begin{array}{l}\text { Tool } \\
\text { No. }\end{array}$ & Overhang/mm & Helix angle/ $\left({ }^{\circ}\right)$ & Teeth number \\
\hline 1 & 50 & 30 & 4 \\
2 & 70 & 30 & 4 \\
3 & 70 & 40 & 4 \\
4 & 70 & 50 & 4 \\
5 & 100 & 30 & 2 \\
6 & 100 & 30 & 3 \\
7 & 100 & 30 & 4 \\
\hline
\end{tabular}

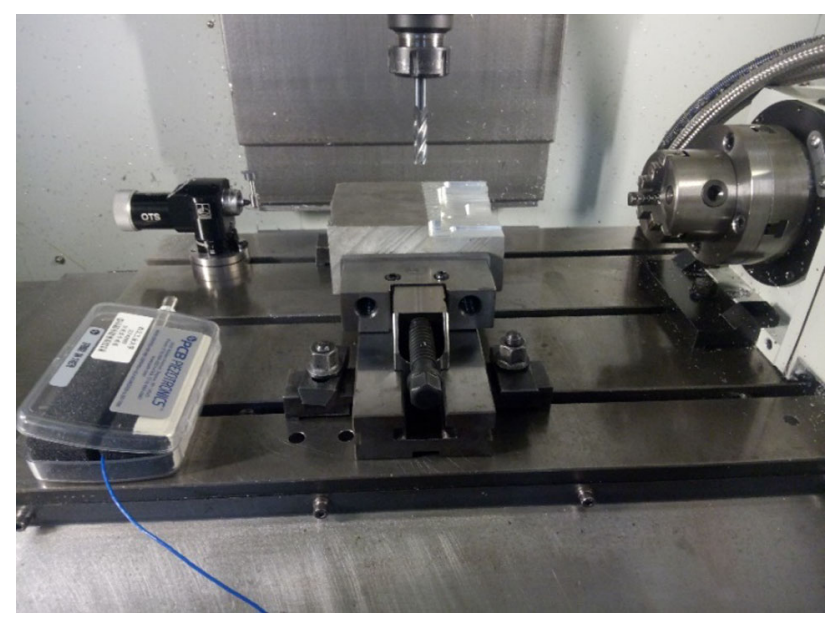

Fig. 9 Experimental setup

used to investigate the effects of the helix angle. Tool Nos. 5-7 were used to study the influence of the number of teeth. The measured sounds together with their Fourier transformation under different amounts of tool overhang, helix angles, and teeth numbers are shown in Figs. 10-12. A summary of the results is listed in Table 7 .

As a control factor, a helix angle of $30^{\circ}$ can lead to a larger axial depth of cut. In addition, a tool with two teeth is better than one with three or four teeth, and a tool overhang of $50 \mathrm{~mm}$ is better than the other two tool overhang lengths. The sequence of the three control factors affecting the cutting stability was verified by analyzing the changes in the critical axial depth of a cut under all levels of the control factors. The critical axial depth of a cut varies from $1.2 \mathrm{~mm}$ to $1.5 \mathrm{~mm}$ or $1.8 \mathrm{~mm}$ when the helix angle varies from $30^{\circ}$ to $40^{\circ}$ or $50^{\circ}$. Under the condition of two, three, or four teeth, the critical axial depth of a cut is $1.4 \mathrm{~mm}, 0.8 \mathrm{~mm}$, and $0.4 \mathrm{~mm}$, respectively. When the tool overhang is $100 \mathrm{~mm}$ or $70 \mathrm{~mm}$, the critical axial depth of the cut is $0.4 \mathrm{~mm}$ or $2.8 \mathrm{~mm}$, whereas the cutting process is stable when the axial depth of the cut is $5 \mathrm{~mm}$ with a tool overhang of $50 \mathrm{~mm}$. From the phenomena mentioned above, it can be concluded that the helix angle has a small effect on the critical axial depth of the cut, whereas the tool overhang has a significant effect on the cutting stability because the critical axial depth of the cut changes greatly with the change in tool overhang. That is, the sequence of the three control factors is the tool overhang, the number of teeth, and the helix angle. In summary, Table 7 shows the same conclusion as that obtained from the simulations described in Sect. 3.

It should be mentioned that the predicted critical axial depth of a cut is only slightly smaller than the actually measured result. For example, the predicted critical value of $0.8 \mathrm{~mm}$ is less than the measured result of $1.3 \mathrm{~mm}$ for tool No. 3. This phenomenon can be attributed to the following two reasons. Firstly, the SLDs shown in Figs. 6-8 are predicted using the modal parameters of the tool point, which are usually measured or calculated under the free status of a cantilevered cutter. For example, in this work, the FRFs are calculated using the proposed theoretical method. As can be seen from Fig. 1, the tool point end of the cutter is under a free state. However, once the cutter is under the actual cutting process, it will make contact with the workpiece, which in turn provides a slight support to the cutter. Correspondingly, the stiffness of the tool point is slightly increased. As a result, the actually observed critical axial depth of the cut is slightly increased, as observed during the experiment. Secondly, as reported in Refs. $[27,28]$, it is actually quite difficult to strictly determine the real critical axial depth of a cut through experimental means because the machining processes are influenced by their complicated environments. That is, there exists a fuzzy region in which the stability of the machining process cannot be strictly determined experimentally. It should be pointed out that in our observations, the difference between the predicted and measured critical axial depth of a cut is about $0.5 \mathrm{~mm}$, which is a relatively small value for practical machining, and can be recognized as being within the fuzzy domain. Because of these two factors above, a difference between the predicted and measured results occurs.

It should also be mentioned that, as described above, relatively small axial depths of a cut were adopted in both the simulation and experimental verifications. Actually, the use of small values is determined based on the dynamic response of the selected tool-spindle-holder system, as can be observed from Figs. 2-4. Under these types of cutting conditions, the phenomenon of interrupted machining is more obvious, and thus, adopting a smaller number of teeth can increase the process stability because it means more time for energy dissipation. This indicates that the use of a smaller teeth number can increase the process stability, which can also be seen from the above verifications. It is worth noting that this conclusion is reached only when considering the cutting stability. This means that if the feed 


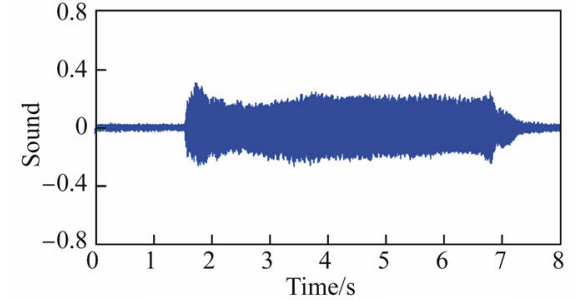

(a) Overhang $50 \mathrm{~mm}, a_{\mathrm{p}}=4.0 \mathrm{~mm}$

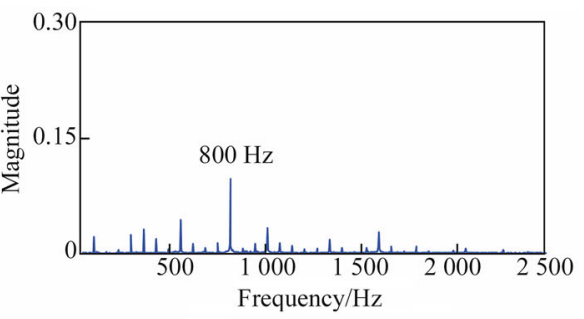

(c) FFT of Fig. 10(a)

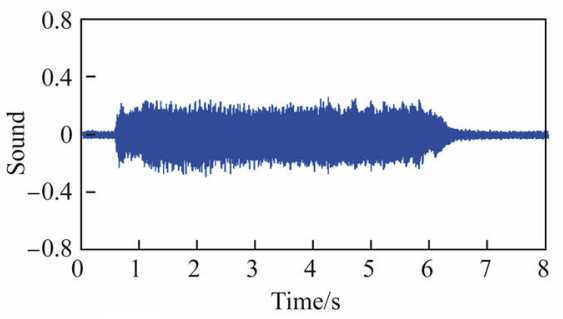

(e) Overhang $70 \mathrm{~mm}, a_{\mathrm{p}}=2.5 \mathrm{~mm}$

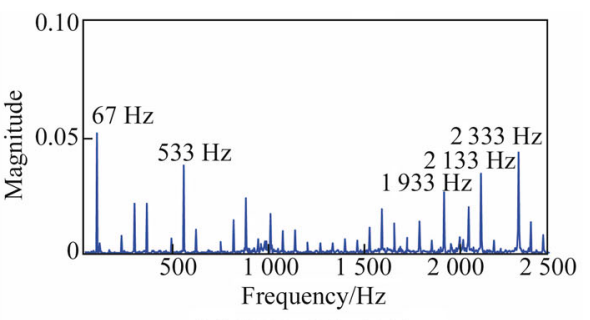

(g) FFT of Fig. 10(e)

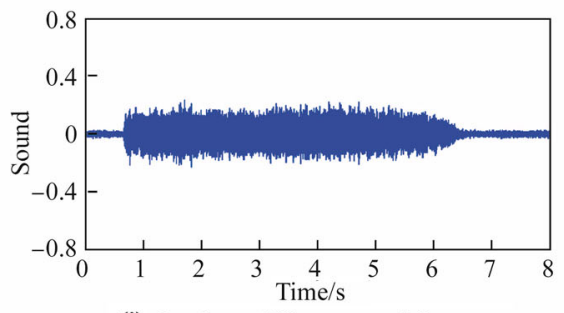

(i) Overhang $100 \mathrm{~mm}, a_{\mathrm{p}}=0.3 \mathrm{~mm}$

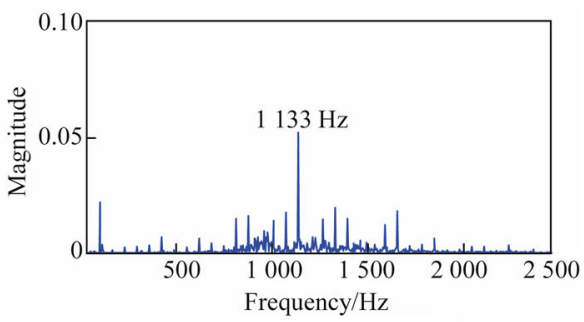

(k) FFT of Fig. 10(i)

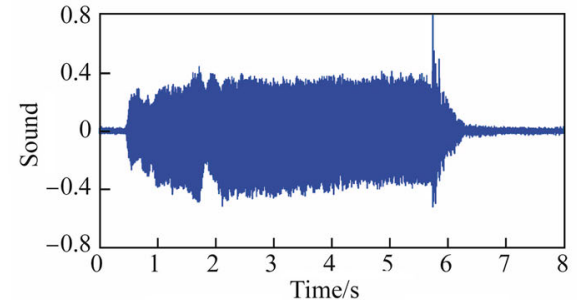

(b) Overhang $50 \mathrm{~mm}, a_{\mathrm{p}}=4.0 \mathrm{~mm}$

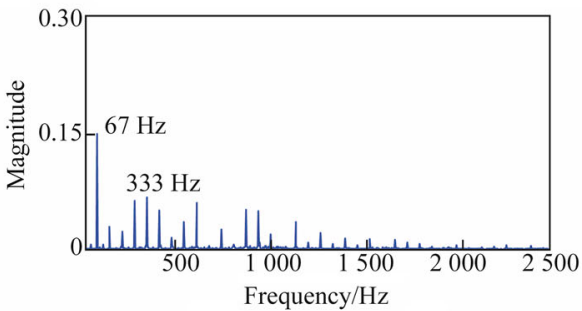

(d) FFT of Fig. 10(b)

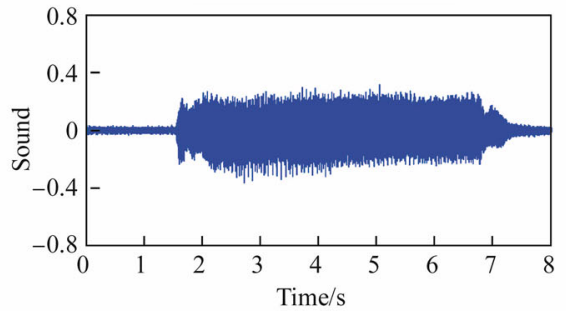

(f) Overhang $70 \mathrm{~mm}, a_{\mathrm{p}}=2.8 \mathrm{~m}$

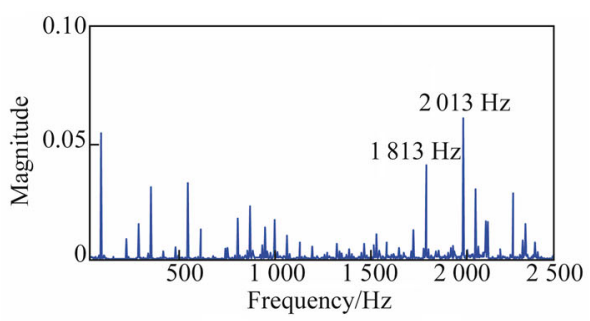

(h) FFT of Fig. 10(f)

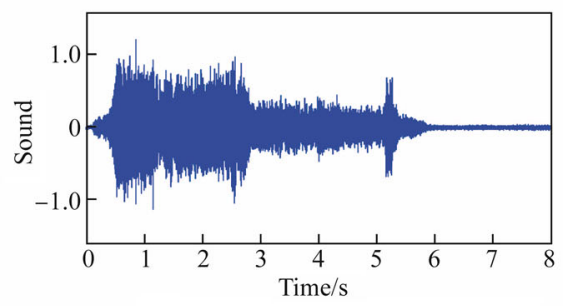

(j) Overhang $100 \mathrm{~mm}, a_{\mathrm{p}}=0.4 \mathrm{~mm}$

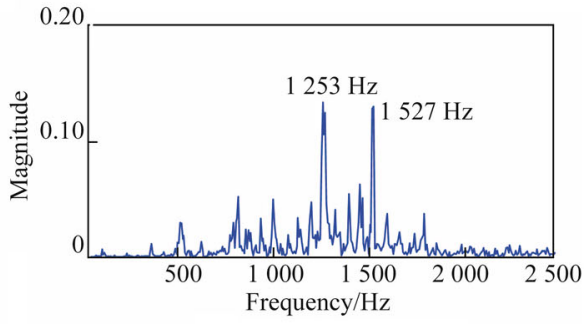

(I) FFT of Fig. 10(j)

Fig. 10 Measured sounds together with their Fourier transformation under different tool overhangs and axial depths of cut $\left(a_{\mathrm{p}}\right)$ 


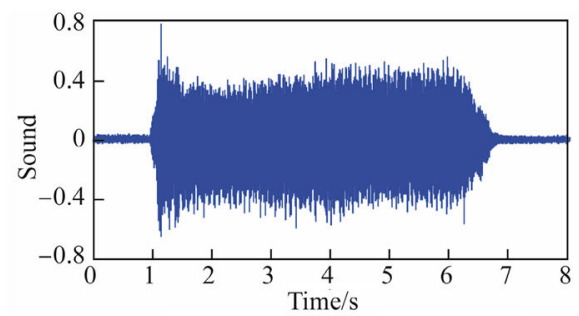

(a) Helix angle $30^{\circ}, a_{\mathrm{p}}=1.5 \mathrm{~mm}$

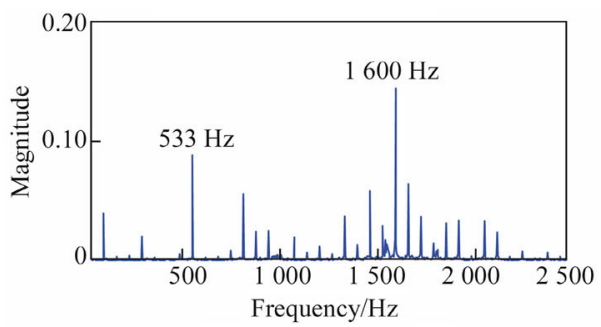

(c) FFT of Fig. 11(a)

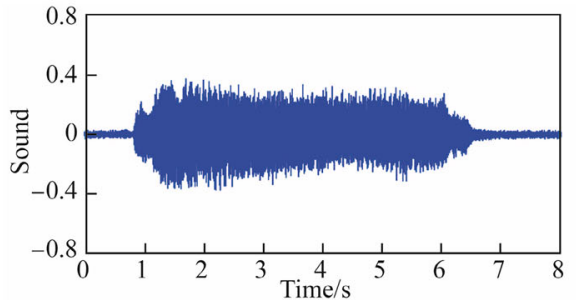

(e) Helix angle $40^{\circ}, a_{\mathrm{p}}=1.3 \mathrm{~mm}$

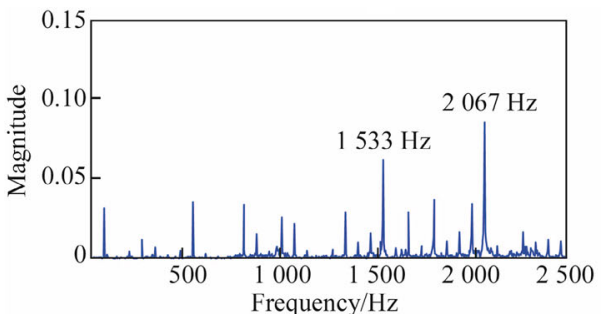

(g) FFT of Fig. 11(e)

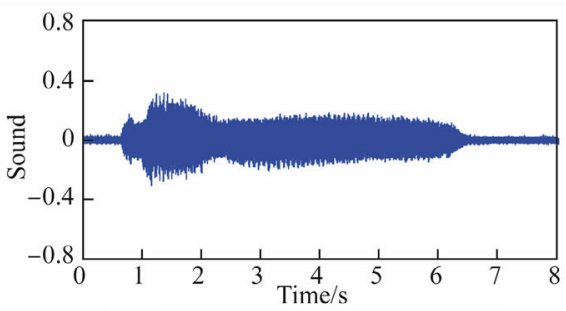

(i) Helix angle $50^{\circ}, a_{\mathrm{p}}=1.0 \mathrm{~mm}$

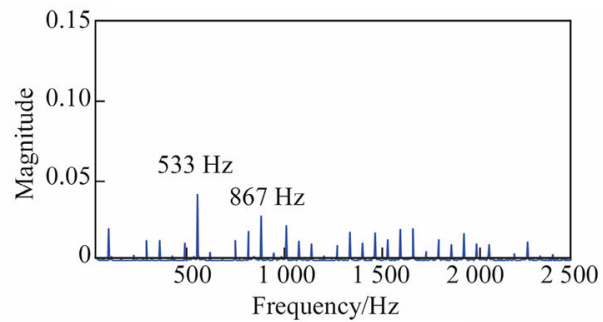

(k) FFT of Fig.11(i)

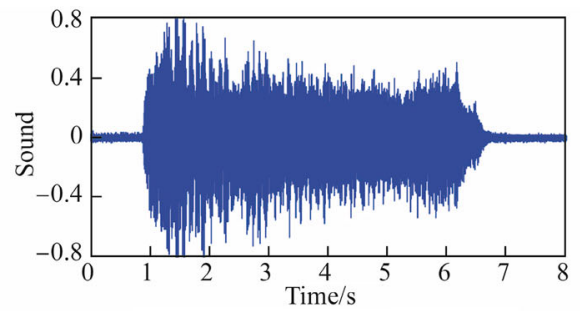

(b) Helix angle $30^{\circ}, a_{\mathrm{p}}=1.8 \mathrm{~mm}$

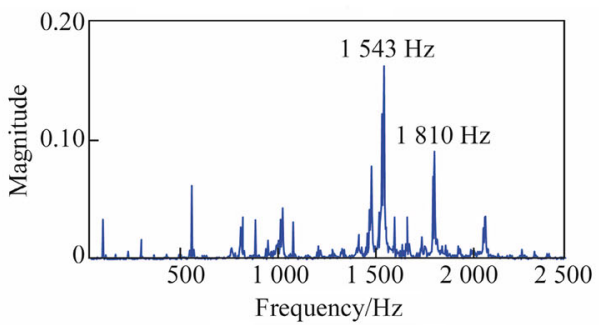

(d) FFT of Fig.11(b)

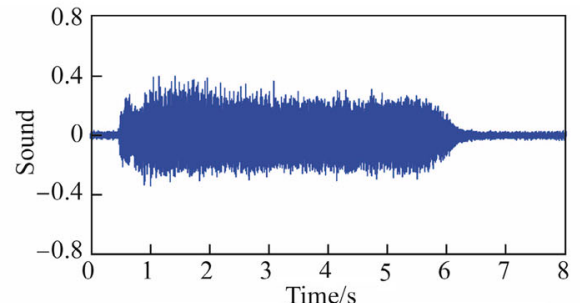

(f) Helix angle $30^{\circ}, a_{\mathrm{p}}=1.5 \mathrm{~mm}$

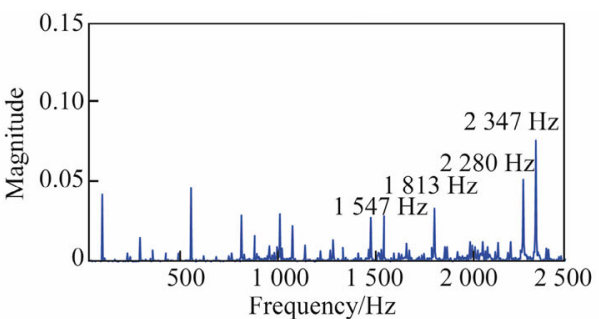

(h) FFT of Fig. 11(f)

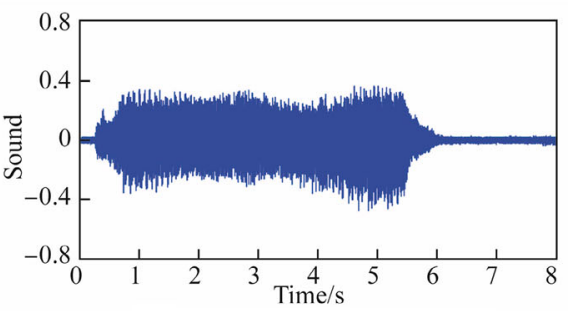

(j) Helix angle $50^{\circ}, a_{\mathrm{p}}=1.2 \mathrm{~mm}$

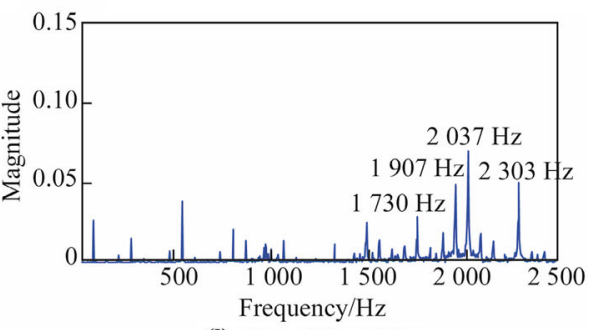

(I) FFT of Fig. 11(j)

Fig. 11 Measured sounds together with their Fourier transformation under different helix angles and axial depths of cut $\left(a_{\mathrm{p}}\right)$ 


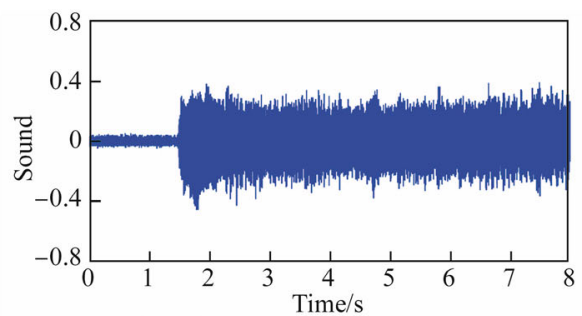

(a) Teeth number $2, a_{\mathrm{p}}=1.2 \mathrm{~mm}$

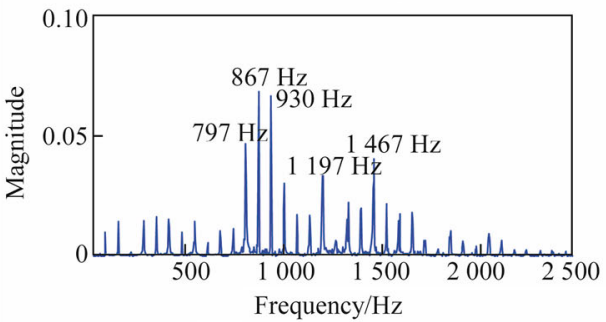

(c) FFT of Fig. 12(a)

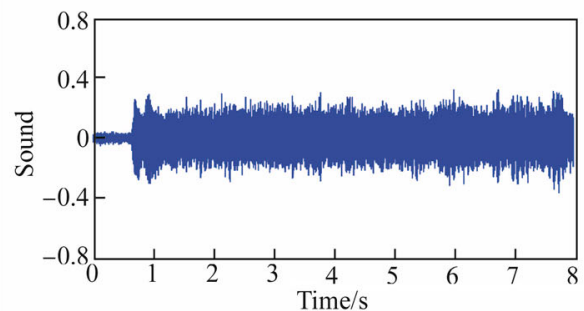

(e) Teeth number $3, a_{\mathrm{p}}=0.6 \mathrm{~mm}$

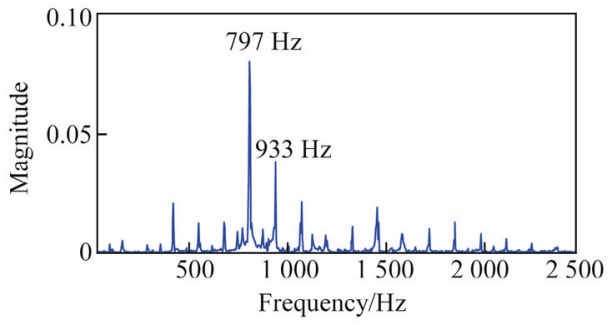

(g) FFT of Fig. 12(e)

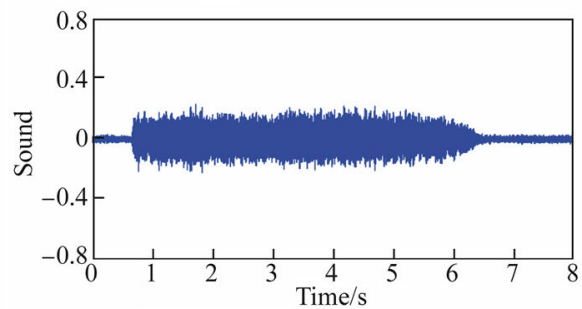

(i) Teeth number $4, a_{\mathrm{p}}=0.3 \mathrm{~mm}$

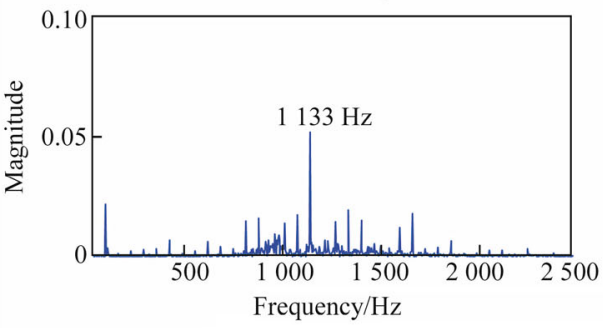

(k) FFT of Fig. 12(i)

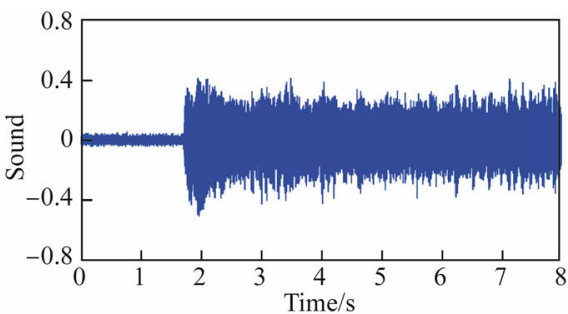

(b) Teeth number $2, a_{\mathrm{p}}=1.4 \mathrm{~mm}$

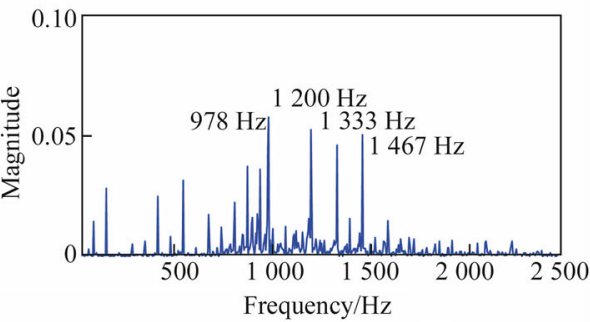

(d) FFT of Fig. 12(b)

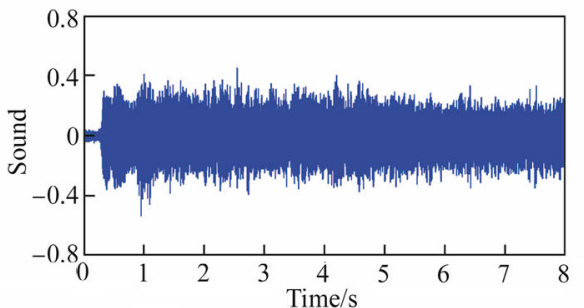

(f) Teeth number $3, a_{\mathrm{p}}=0.8 \mathrm{~mm}$

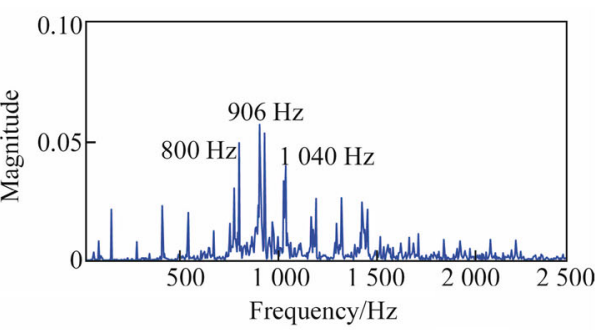

(h) FFT of Fig. 12(f)

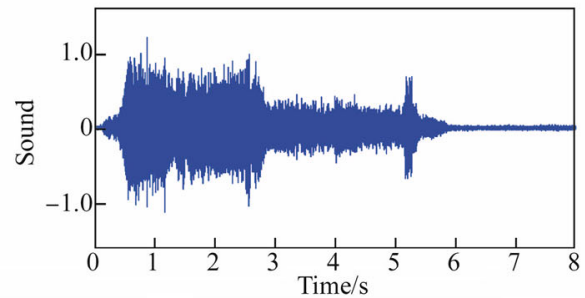

(j) Teeth number $4, a_{\mathrm{p}}=0.4 \mathrm{~mm}$

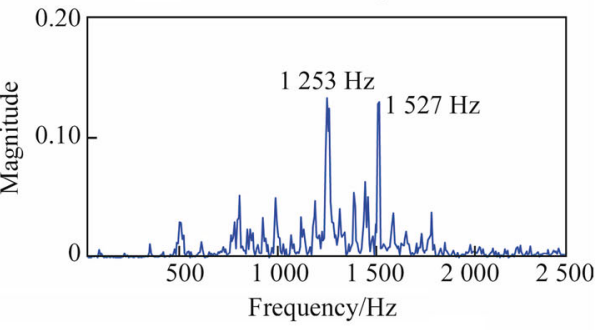

(I) FFT of Fig. 12(j)

Fig. 12 Measured sounds together with their Fourier transformation under different teeth numbers and axial depths of cut $\left(a_{\mathrm{p}}\right)$ 
Table 7 Summary of the experiment results

\begin{tabular}{|c|c|c|c|c|c|}
\hline Control factors & Level values & Tooth number & Axial depth/mm & Dominant frequency/Hz & $\mathrm{SC}$ \\
\hline \multirow[t]{6}{*}{ Helix angle } & \multirow[t]{2}{*}{$30^{\circ}$} & \multirow[t]{2}{*}{2} & 1.5 & 533,1600 & $\mathrm{~S}$ \\
\hline & & & 1.8 & 1543,1810 & $\mathrm{C}$ \\
\hline & \multirow[t]{2}{*}{$40^{\circ}$} & \multirow[t]{2}{*}{3} & 1.3 & 1533,2067 & $\mathrm{~S}$ \\
\hline & & & 1.5 & 2 280, 2 347, etc. & $\mathrm{C}$ \\
\hline & \multirow[t]{2}{*}{$50^{\circ}$} & \multirow[t]{2}{*}{4} & 1.0 & 533,867 & $\mathrm{~S}$ \\
\hline & & & 1.2 & 1 970, 2 037, etc. & $\mathrm{C}$ \\
\hline \multirow[t]{6}{*}{ Teeth number } & \multirow[t]{2}{*}{2} & \multirow[t]{2}{*}{5} & 1.2 & 867,930 & $\mathrm{~S}$ \\
\hline & & & 1.4 & 978 & $\mathrm{C}$ \\
\hline & \multirow[t]{2}{*}{3} & \multirow[t]{2}{*}{6} & 0.6 & 797,933 & $\mathrm{~S}$ \\
\hline & & & 0.8 & 906,1040 & $\mathrm{C}$ \\
\hline & \multirow[t]{2}{*}{4} & \multirow[t]{2}{*}{7} & 0.3 & 1133 & $\mathrm{~S}$ \\
\hline & & & 0.4 & 1253,1527 & $\mathrm{C}$ \\
\hline \multirow[t]{6}{*}{ Tool overhang } & \multirow[t]{2}{*}{$50 \mathrm{~mm}$} & \multirow[t]{2}{*}{1} & 4.0 & 800 & $\mathrm{~S}$ \\
\hline & & & 5.0 & 67,333 & $\mathrm{~S}$ \\
\hline & \multirow[t]{2}{*}{$70 \mathrm{~mm}$} & \multirow[t]{2}{*}{2} & 2.5 & 67,533 , etc. & $\mathrm{S}$ \\
\hline & & & 2.8 & 1813,2013 & $\mathrm{C}$ \\
\hline & \multirow[t]{2}{*}{$100 \mathrm{~mm}$} & \multirow[t]{2}{*}{7} & 0.3 & 1133 & $\mathrm{~S}$ \\
\hline & & & 0.4 & 1253,1527 & $\mathrm{C}$ \\
\hline
\end{tabular}

"SC" denotes whether the cutting process is stable; "S" denotes a stable cutting process; "C" denotes the chatter occurring in cutting process

rate and spindle speed are fixed, the use of a smaller number of teeth will lead to a reduction in productivity. That is, this conclusion is not related to whether the productivity will be correspondingly increased. However, finding a balance between increased productivity and stability should be properly investigated, and remains an open problem to be further explored.

Finally, it is worth remarking that directly comparing the results of each single SLD in an orthogonal array is not suggested because the parameters of concern for each test are not controlled by a single factor. Usually, after completing the tests in an orthogonal array, an orthogonal analysis, which comprehensively includes the influences of all results, is conducted to study the results. The analysis results are shown in Tables 4 and 5, from which it can be concluded that the selection of a tool overhang of $50 \mathrm{~mm}$ is better than that of $70 \mathrm{~mm}$ or $100 \mathrm{~mm}$. In addition, it was also observed from the experiments that a $50 \mathrm{~mm}$ overhang has a larger critical depth of a cut than a tool with a $70 \mathrm{~mm}$ overhang. This phenomenon agrees with the analyzed results.

\section{Conclusions}

Geometrical tool parameters have a significant impact on the cutting process, and finding the optimal geometrical tool parameters can lead to a high cutting efficiency and quality. This paper studies the effects of geometrical tool parameters on the cutting stability. A method to calculate the FRF of a tool point that avoided complex and tedious impact experiments and improved the efficiency was adopted. SLDs were simulated through varying the geometrical tool parameters based on the FRFs. Using the Taguchi design method, it was found that the dominant parameter affecting the cutting stability is the tool overhang. The second-most dominant parameter is the number of teeth, with the helix angle being the third parameter of importance. A series of experiments using different combinations of geometrical tool parameters were carried out. Observations from the experiments verify the conclusions described above.

Acknowledgements This research was supported by the National Natural Science Foundation of China (Grant Nos. 51675440, 11432011 and 11620101002), the National Key Research and Development Program of China (Grant No. 3102018gxc025).

Open Access This article is distributed under the terms of the Creative Commons Attribution 4.0 International License (http://crea tivecommons.org/licenses/by/4.0/), which permits unrestricted use, distribution, and reproduction in any medium, provided you give appropriate credit to the original author(s) and the source, provide a link to the Creative Commons license, and indicate if changes were made.

\section{References}

1. Altintas Y (2000) Manufacturing automation. 2nd edn. Cambridge University Press, Cambridge 
2. Wan M, Ma YC, Feng J et al (2016) Study of static and dynamic ploughing mechanisms by establishing generalized model with static milling forces. Int J Mech Sci 114:120-131

3. Yang YQ, Dai W, Liu Q (2015) Design and implementation of two-degree-of-freedom tuned mass damper in milling vibration mistigation. J Sound Vib 335:78-88

4. Wan M, Feng J, Ma YC et al (2017) Identification of milling process damping using operational modal analysis. Int $\mathrm{J}$ Mach Tool Manuf 122:120-131

5. Erturk A, Ozguven HN, Budak E (2006) Analytical modeling of spindle-tool dynamics on machine tools using Timoshenko beam model and receptance coupling for the prediction of tool point FRF. Int J Mach Tool Manuf 46:1901-1912

6. Zhou HM, Wang CY, Zhao ZY (2007) Dynamic characteristics of conjunction of lengthened shrink-fit holder and cutting tool in high-speed milling. J Mater Process Technol 207:154-162

7. Engin S, Altintas Y (2001) Mechanics and dynamics of general milling cutters. Part I: helical end mills. Int J Mach Tool Manuf 41:2195-2212

8. Altintas Y, Engin S, Budak E (1999) Analytical stability prediction and design of variable pitch cutters. J Manuf Sci E-T ASME 121:173-178

9. Budak E (2003) An analytical design method for milling cutters with nonconstant pitch to increase stability, part 1: theory. J Manuf Sci E-T ASME 125:29-34

10. Sellmeier V, Denkena B (2011) Stable islands in the stability chart of milling process due to unequal tooth pitch. Int J Mach Tool Manuf 51:152-164

11. Shirase K, Altintas Y (1996) Cutting force and dimensional surface error generation in peripheral milling with variable pitch helical end mills. Int J Mach Tool Manuf 36:567-584

12. Dombovari Z, Stepan G (2012) The effect of helix angle variation on milling stability. J Manuf Sci E-T ASME 134:051015

13. Subramanian M, Sakthivel M, Sooryaprakash K et al (2013) Optimization of end mill tool gerometry parameters for Al7075T6 machining operations based on vibration amplitude by response surface methodology. Measurement 46:4005-4022

14. Li GX, Liu Q (2008) Experiment and simulation of cutter geometric parameter affecting stability in milling process. Trans Chin Soc Agric Mach 39:194-197

15. Wei ZY, Gao DQ, Mao ZY et al (2010) High-speed milling system stability study based on the cutting parameters. Modul Mach Tool Autom Manuf Tech 11:16-18
16. Neseli S, Yadiz S, Turkes E (2011) Optimizations of geometry parameters for turning operations based on the response surface methodology. Measurement 44:580-587

17. Alauddin M, El Baradie MA (1997) Tool life model for end milling steel (190 BHN). J Mater Process Technol 68:50-59

18. Zeng JW, Ren JX, Yin J et al (2013) Research on tool geometry optimization of TC18 titanium alloy milling. Avia Precis Manuf Technol 49:37-40

19. Schmitz T, Donaldson R (2000) Predicting high-speed machining dynamics by substructure analysis. CIRP Ann Manuf Technol 49:303-308

20. Wan M, Ma YC, Zhang WH et al (2015) Study on the construction mechanism of stability lobes in milling process with multiple modes. Int J Adv Manuf Technol 79:589-603

21. Insperger T, Stepan G (2002) Semi-discretization method for delayed systems. Int J Numer Methods Eng 55:503-518

22. Insperger $T$ (2010) Full-discretization and semi-discretization for milling stability prediction: some comments. Int J Mach Tool Manuf 50:658-662

23. Zhang JZ, Chen JC, Kirby ED (2007) Surface roughness optimization in an end-milling operation using the Taguchi design method. J Mater Process Technol 184:233-239

24. Yang WH, Tarng YS (1998) Design optimization of cutting parameters for turning operations based on the Taguchi method. J Mater Process Technol 84:122-129

25. Selvaraj DP, Chandramohan P (2010) Optimization of surface roughness of AISI 304 austenitic stainless steel in dry turning operation using Taguchi design method. J Eng Sci Technol 5:293-301

26. Wan M, Dang XB, Zhang WH et al (2018) Optimization and improvement of stable processing condition by attaching additional masses for milling of thin-walled workpiece. Mech Syst Signal Process 103:196-215

27. Ahmadi K, Altintas Y (2014) Identification of machining process damping using output-only modal analysis. J Manuf Sci E-T ASME 136:051017

28. Eksioglu C, Kilic ZM, Altintas Y (2012) Discrete-time prediction of chatter stability, cutting forces, and surface location errors in flexible milling systems. J Manuf Sci E-T ASME 134:061006 